\title{
Symptomatic cataplexy
}

\author{
MILNE ANDERSON AND M. V. SALMON \\ From the Midland Centre for Neurosurgery and Neurology, Smethwick, Warley, West Midlands
}

SUMMARY The case is described of a man who developed attacks of cataplexy, narcolepsy, and sleep paralysis because of a microglioma which infiltrated the walls and floor of the IIIrd ventricle and the upper brain stem. The mechanisms by which the pathology is related to the symptoms are discussed.

In 1880 Gélineau coined the term 'narcolepsy' and related the clinical details of two patients who suffered from the condition, acknowledging that an account of the first had been published by Caffé in 1862. Henneberg (1916) described cataplexy with narcolepsy, and in the 1920s sleep paralysis became associated with the disease. Despite widespread interest and a large literature the cause remains unknown, and the vast majority of cases have no known structural basis. In the minority narcolepsy is said to be 'secondary' to various pathological conditions-to injury (Drake, 1949), to brain stem infarction (Van Bogaert, 1926), to third ventricular tumour (Fulton and Bailey, 1929), to polioencephalitis (Pohl, 1966)-or has occurred with other neurological disease, disseminated sclerosis (Ekbom, 1966; Berg and Hanley, 1963), and cerebellar haemangioblastoma (Tridon et al., 1969). We do not know of a case of primary narcolepsy coming to necropsy, and postmortem details of secondary narcolepsy are distinctly rare (Van Bogaert, 1926; Fulton and Bailey, 1929; Benedek and Juba, 1943; Pohl, 1966). Levin (1932) commented that there had been no necropsy report on cataplexy. We find this statement still true, and, so far as we know, the case described here is the first.

\section{Case report}

In June 1970, nine months before admission to hospital, a 23 year old male laboratory technician developed diplopia when he became tired, and at these times relatives would notice his eyes diverge. In the next three months strabismus increased and his eyelids drooped. His sleep rhythm became disturbed - he was unable to fall asleep at night, and if he

eventually did so would waken in the early hours o the morning and be unable to sleep again. In the daytime he would have uncontrollable urges to sleep but he could be easily roused and seldom slept for more than 30 minutes. Two months later he began to have frequent attacks of sleep paralysis. He would waken and, although fully conscious and aware of his surroundings, he was unable to move any limb or muscle for as long as 30 seconds, which he found frightening. He developed polydypsia and polyuria and would drink as much as seven pints of water each night and rather more during the day. Although he always denied feeling any itch, an insatiable desire to scratch resulted in the production of numerous cutaneous sores. Cataplectic attacks now occurred. He would abruptly become toneless and fall to the ground, injuring himself on several occasions. He never lost consciousness and the attacks would occur spontaneously or be induced by startlefor example, by sudden noise or shock. He did not think they could be induced by laughter or anger. Unsteadiness of gait became evident, strabismus increased, and he developed oscillopsia on looking downwards.

He was admitted to hospital on 25 March 1971. Examination showed a fully conscious youth. If left alone in his room he would soon fall asleep but could be roused easily. Optic fundi were normal; there was bilateral ptosis, paresis of conjugate downward gaze, vertical nystagmus on upward gaze, abduction paresis of the right eye, and bilateral paresis of adduction (Fig. 1) and paresis of convergence. The right pupil was slightly larger than the left and each reacted to light and accommodation. There was mild left facial weakness and other cranial nerves were normal. Ataxia and dysdiadochokinesis of left hand and leg were evident, left leg tendon reflexes were increased, and both plantar responses were flexor. General physical examination was normal, except for numer- 


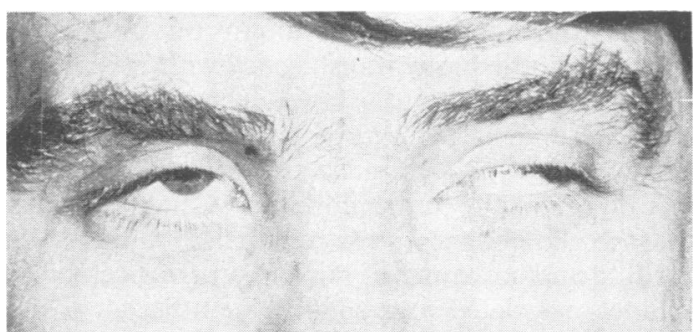

Fig. 1 -Attempted right lateral gaze showing bilateral ptosis, paresis of abduction of the right eye and superficial skin ulceration.

ous superficial cutaneous excoriations caused by scratching. Blood pressure was $130 / 80 \mathrm{mmHg}$.

The following investigations were normal: $\mathrm{Hb}$, WBC, ESR, urea, blood sugar, protein-bound iodine, and radiographs of skull and chest. Hypoglycaemia of $1.61 \mathrm{nmol} / \mathrm{l}$, induced by insulin, provoked no rise of serum cortisol levels. EEG (without sleep recording) showed bilateral alpha activity, better formed on the right than the left, and bilateral delta waves appeared on overbreathing. Technetium isotope brain scan showed a deeply placed central abnormal uptake (Figs. 2a, b). Left carotid angiography showed enlargement of the left lateral ventricle and elevation of the venous angle. Pneumoventriculography showed marked dilatation of the lateral ventricles and a mass arising from the floor of the third ventricle displacing the aqueduct upwards and backwards, and extending into the thalamus on the right (Fig. 3).

These findings were thought to indicate an intrinsic lesion, probably neoplastic, of the upper brain stem and hypothalamus. Surgical opinion decided against biopsy or drainage procedure. The diabetes insipidus was controlled by alternate day injections of pitressin, and satisfactory nocturnal sleep was obtained with chlorpromazine. For the attacks of cataplexy which would occur as often as 20 times per day he was given

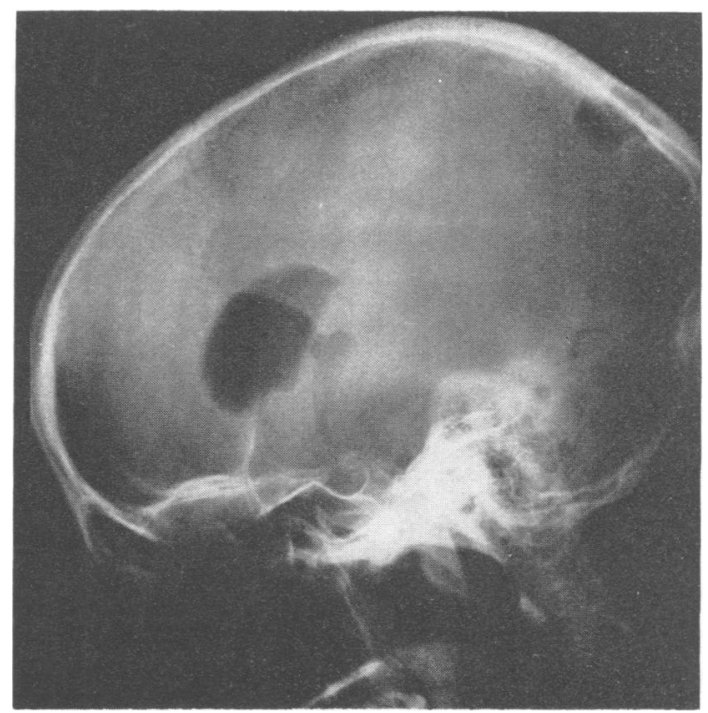

Fig. 3 Left lateral view of pneumoventriculogram showing hydrocephalus and a mass arising from the floor of the IIIrd ventricle.

imipramine, $25 \mathrm{mg}$ thrice daily. Within 24 hours they ceased and did not recur for the rest of his life. The compulsion to scratch ceased, narcolepsy and sleep paralysis improved but did not disappear, and he went home on 29 September 1971.

Over the next two months he slowly deteriorated, ataxia and ocular palsies increased, narcolepsy and sleep paralysis attacks continued, and the compulsion to scratch returned, despite continuation of the medication. He was admitted to another hospital, developed bronchopneumonia, and died on 29 November 1971.

NECROPSY (Dr S. P. B. Way)

The cause of death was bilateral basal bronchopneumonia and fibrinous pleurisy.

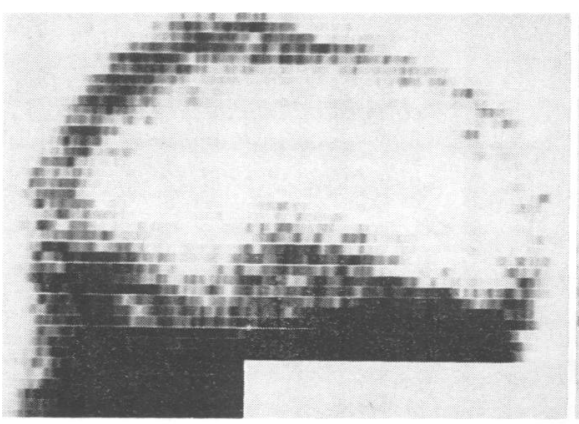

(a)

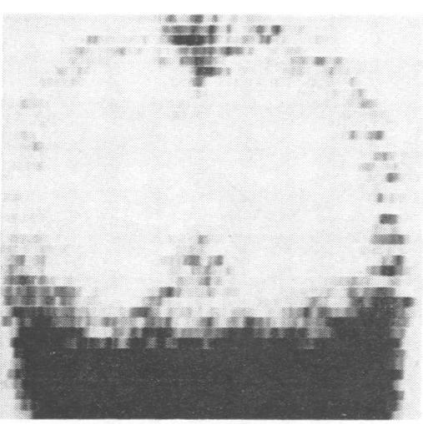

(b)
Fig. 2 (a) right lateral and $(b)$ anteroposterior view of technetium isotope brain scan showing deeply-placed central abnormal uptake. 


\section{Brain}

After fixation, slight generalised opacity of the leptomeninges was noted, most obvious in the region of the basal cistern. On coronal slicing (Fig. 4) major abnormalities were limited to the area of the IIIrd ventricle, the pituitary stalk, the septum pellucidum, the adjacent portions of the internal capsule, lenticular nuclei, and the thalamus, much more evident on the right than on the left. The right mammillary body was twice the size of the left, which was approximately normal (Fig. 5). At this level, there was softening with formation of small cyst spaces in the right pes pedunculis and corpus subthalamicus. Within the upper brain stem the region of the right red nucleus and the substantia nigra on both sides showed a mottled grey translucency with broadening and depigmentation of the latter. The walls and floor of the IIIrd ventricle, particularly on the right, were thickened by grey, granular tissue which extended rostrally into the optic chiasma. Caudal to this, macroscopic changes were minimal, but there was mottling and softening of the left superior cerebellar peduncle restricted to a small zone adjacent to the leptomeningeal surface.

\section{Microscopy}

The lesion in the floor of the third ventricle and adjacent structures was a microglioma, chiefly around

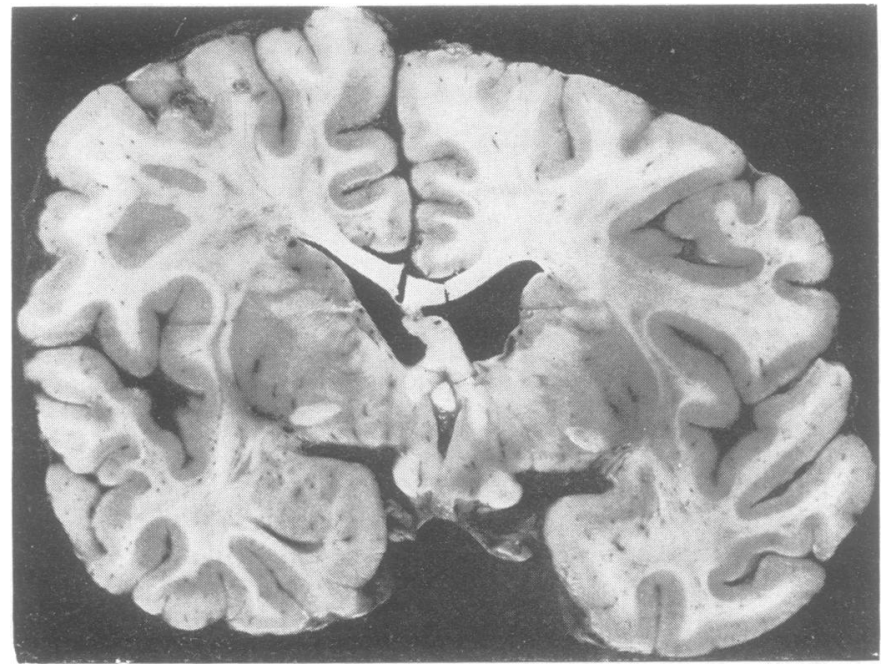

Fig. 4 Coronal slice showing thickening of the pituitary stalk, floor and walls of the third ventricle and separation of the posterior limbs of the chiasma.

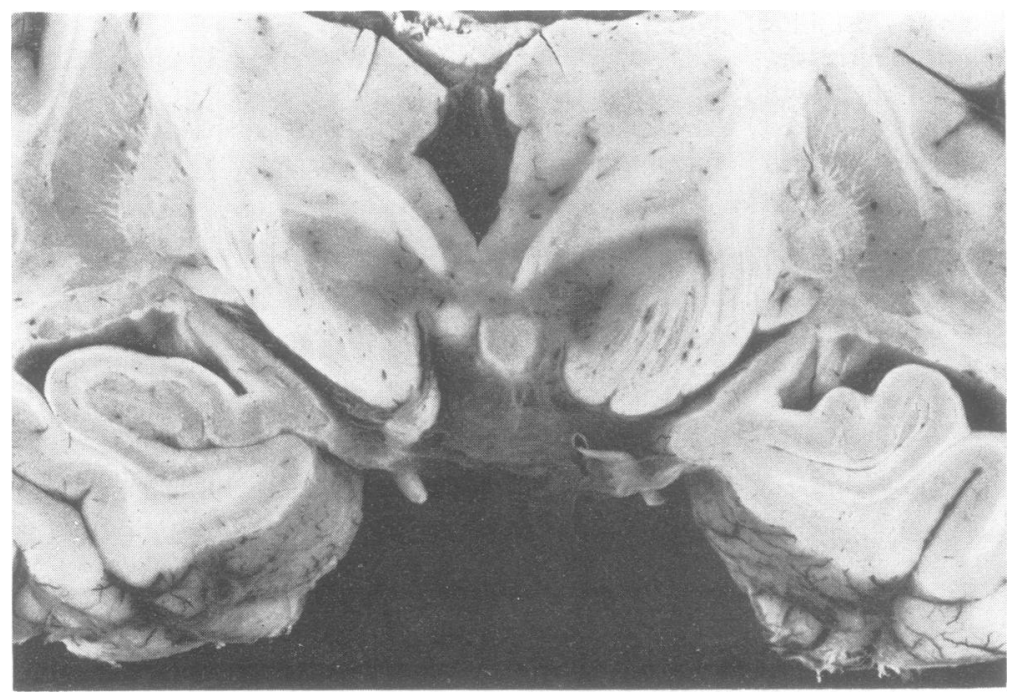

Fig. 5 Coronal slice through the corpora mammillaria showing more extensive tumour infiltration on the right. 
blood vessels and in the leptomeninges of the basal cisterns where there was admixture with fairly numerous lymphocytes. Tumour extended along proliferating blood vessels (Fig. 6) and diffusely through cerebral substance in many areas. Nowhere was the cellularity marked except in the Virchow-Robin spaces. Some cells had large or even gigantic nuclei (Fig. 7), frequently with intranuclear inclusions (Fig. 8). They were of the irregular granular type now recognised as cytoplasmic and due to convolution of the nuclear membrane. At chiasmatic level, particularly on the right, the tumour had formed cavities in the thickened floor of the IIIrd ventricle with proteinous coagulum in the cyst spaces, and numerous compound granular corpuscles. In the affected areas the neuronal changes varied from minimal chromatolysis to complete neuronophagia. In the substantia nigra, particularly on the right, the neuronal loss was not complete but was marked by numbers of large, pigment-laden macrophages. In the central pons tumour extended dorsally and caudally, particularly on the left, to involve the locus coeruleus and adjacent nuclei, including the oculomotor. The softening of the left superior cerebellar peduncle was confirmed with slight diffuse tumour locally but no spread into the cerebellum. There was no tumour or other lesion in the medulla.

\section{Discussion}

This patient's clinical signs and symptoms suggested an intrinsic lesion of the upper brainstem and hypothalamus. We believe that the occurrence of narcolepsy, cataplexy, and attacks of sleep paralysis during the course of his illness was not due to chance coincidence but was a direct consequence of structural damage to rostral brain stem reticular nuclei and strongly supports the hypothesis that narcolepsy
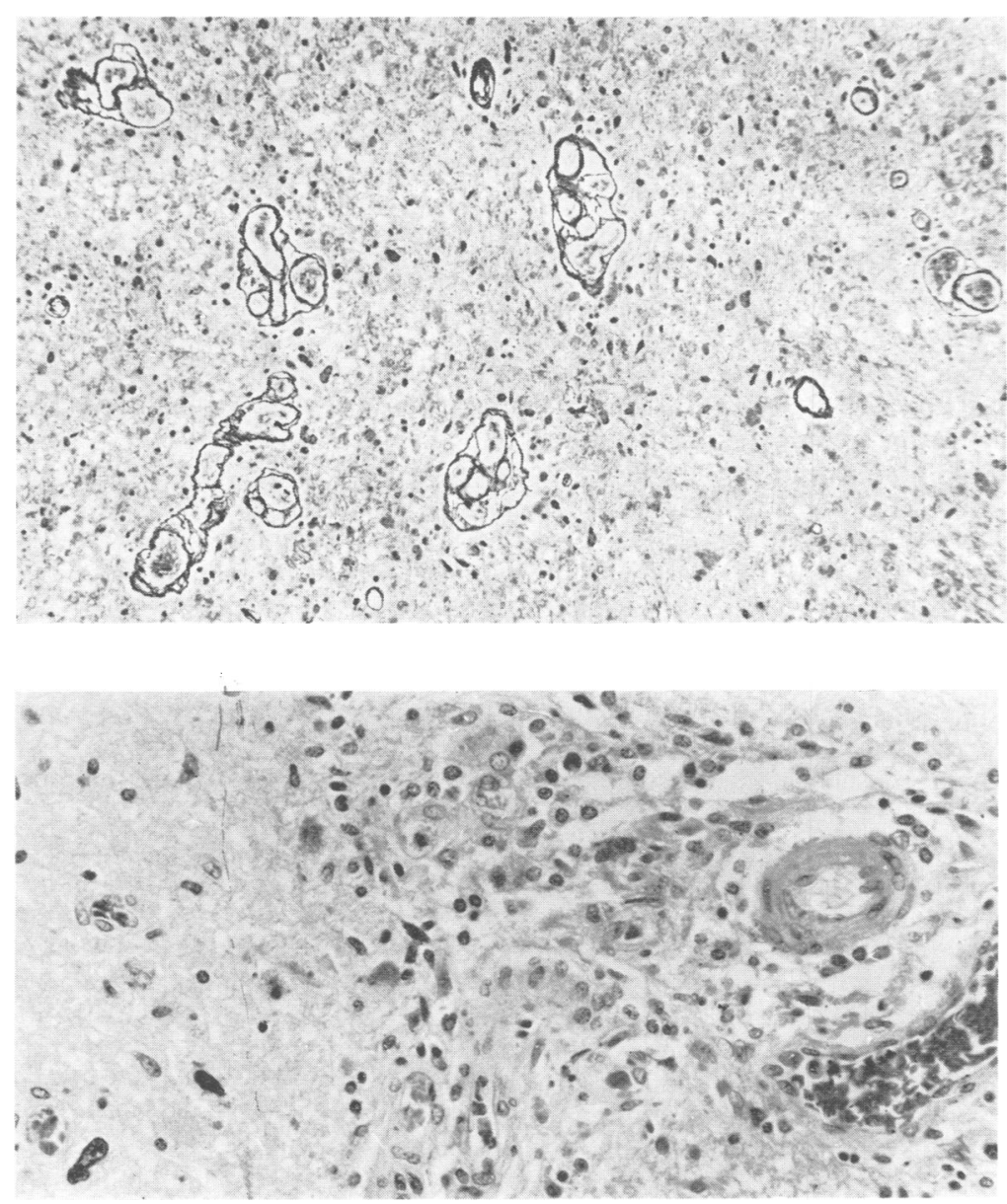

Fig. 6 Proliferation of small vessels, sometimes several in one Virchow-Robin space, and capillaries with tumour nuclei visible in the background. Brain stem, reticulin stain, original magnification $\times 380$.

Fig. 7 Perivascular tumour with capillary proliferation and endothelial hyperplasia, scattered large tumour cells with bizarre nuclei particularly in white matter to left of field. $H$ and $E$, original magnification $\times 530$. 


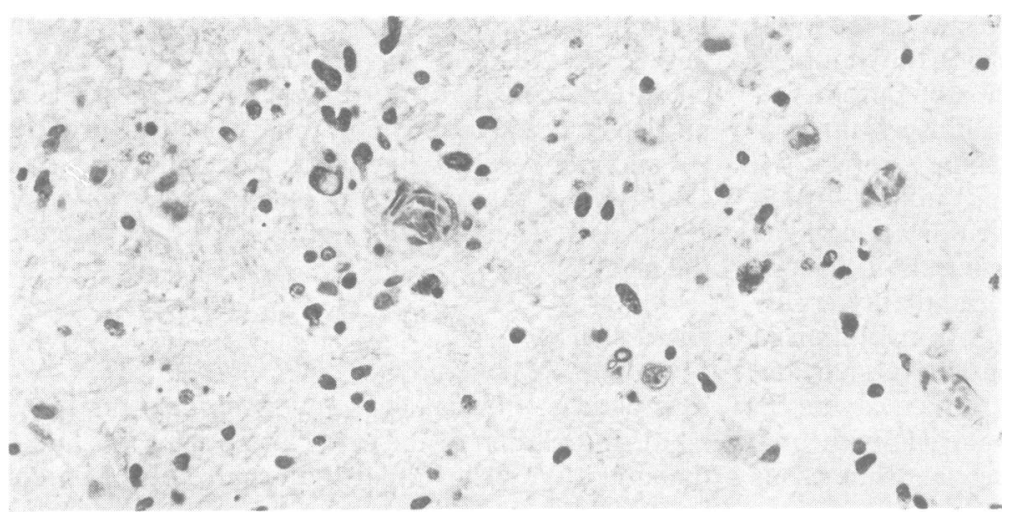

Fig. 8 From the region of the left locus coeruleus; no residual neurones in this field, large abnormal nuclei of tumour microglia throughout the centre of the field, particularly around the small vessel where one shows a large, pale intranuclear inclusion. $H V G$, original magnification $\times 530$. results from functional derangement of the reticular activating system.

Recent polygraphic studies of narcolepsy and of sleep in normal people have provided the basis for current aetiological speculation. Rechtschaffen et al. (1963) found that at onset of sleep, narcoleptics passed straight into stage 1 rapid eye movement (REM) sleep, unlike normal subjects who had an average of 90 minutes of non-rapid eye movement (NREM) sleep before the first REM period. Extrapolating from experiments by Jouvet (1960) on cats they felt that REM sleep in normal humans resulted from triggering of the pontine reticular formation, and in narcoleptics this trigger process might be precocious. Some authors (Dement et al., 1966; Suzuki, 1966) postulate that narcolepsy without accessory symptoms is due to a disturbance of NREM sleep mechanisms, while narcolepsy with accessory symptoms of cataplexy and sleep paralysis results from upset of REM sleep mechanisms. Roth et al. (1969) found that narcolepsy on its own may result from disturbance of either REM or NREM sleep, but agreed that cataplexy and sleep paralysis are manifestations of REM sleep abnormality, and that REM sleep is regulated by the pontine reticular formation.

Cataplexy and sleep paralysis can be regarded as attacks of motor inhibition with loss of muscle tone and areflexia (Rechtschaffen et al., 1963; Dement et al., 1966). Cataplexy and sleep paralysis occur only in relation to REM sleep periods (Hishikawa and Kaneko, 1965), and it may be that they derive from the nucleus locus coeruleus. This portion of the brain stem was markedly involved by the pathological process in this case, and it is tempting to postulate this as the cause of his symptoms.

Disturbance of ocular movement preceded and then evolved apace with the narcoleptic symptoms, and this may imply proximity of a 'sleep centre' to oculomotor nuclei. Several authors (Levin, 1943;
Keefe et al., 1960; Dale and Langworthy, 1964; Chee, 1968) have noted ocular manifestations with narcolepsy, usually diplopia or visual blurring. Van Bogaert (1926) suggested that there may be a sleep centre in the region of the oculomotor nuclei, and commented that, in most of the published cases of sleep problems, there have been associated difficulties with central eye movements. Most normal people when drowsy have noted blurring of vision or diplopia. It is of considerable interest that these ocular manifestations accompany narcolepsy as distinct from cataplexy, and we believe that this indicates physiological if not indeed anatomical proximity of the 'sleep centre' to oculomotor nuclei. This 'sleep centre' is probably that which controls NREM sleep, as the motor inhibition of REM sleep does not include the extraocular muscles-patients in cataplectic attacks can move their eyes.

The pathological features were considered to be neoplastic rather than granulomatous because of the bizarre nature of the microglial nuclei and despite the low cellularity in most areas. Scattered lymphocytes were present but were nowhere numerous. The case described by Pohl (1966) demonstrated changes with some similar features, but was interpreted as inflammatory (an abortive polioencephalitis), not neoplastic.

Imipramine and its derivatives have had the most remarkable beneficial effects in the treatment of cataplexy (Hishikawa et al., 1966; Guilleminault et al., 1974; Parkes et al., 1974; Shapiro, 1975) and it is of interest that these have been extended to symptomatic cataplexy in this case. The mode of action of these drugs in this condition is not understood, but Mitler and Dement (1974) have shown that cholinergic stimulation of the pontine reticular formation in cats can produce a cataplectic response and it is tempting to postulate that the anticholinergic effects of imipramine may counter this.

This case, which we believe to be unique, demon- 
strates that the narcolepsy/cataplexy syndrome may result from a structural lesion affecting the reticular activating system and further strengthens the view that the syndrome is due to derangement of normal activating mechanisms, probably on a biochemical basis.

Thanks are due to Dr Edwin R. Bickerstaff for permission to publish details of this case and for helpful comment, to Dr S. P. B. Way for making available the brain and details of the necropsy, to the technical staff of the Department of Pathology, and to Mrs Margaret Spanswick for secretarial help.

\section{References}

Benedek, L., and Juba, A. (1943). Beiträge zur Pathologie des Diencephalon. Zeitschrift fur die gesamte Neurologie und Psychiatrie, 175, 765-778.

Berg, O., and Hanley, J. (1963). Narcolepsy in two cases of multiple sclerosis. Acta Neurologica Scandinavica, 39, 252-257.

Chee, P. H. (1968). Ocular manifestations of narcolepsy. British Journal of Ophthalmology, 52, 54-56.

Dale, R. T., and Langworthy, O. R. (1964). The narcoleptic tetrad with spontaneous diplopia and strabismus. Neurology (Minneap.), 14, 773-775.

Dement, W., Rechtschaffen, A., and Gulevich, G. (1966). The nature of the narcoleptic sleep attack. Neurology (Minneap.), 16, 18-33.

Drakc, F. R. (1949). Narcolepsy-brief review and report of cases. American Journal of Medical Sciences, 218, 101-114.

Ekbom, K. (1966). Familial multiple sclerosis associated with narcolepsy. Archives of Neurology (Chic.), 15, 337-344.

Fulton, J. F., and Bailey, P. (1929). Tumours in the region of the third ventricle. Journal of Nervous and Mertal Diseases, 69, 1-45, 145-164, 261-277.

Gélineau, E. (1880). De la narcolepsie. Gazette des Hopitaux Civils et Militaires, 53, 626-628.

Guilleminault, C., Wilson, R. A., and Dement, W. C. (1974). A study on cataplexy. Archives of Neurology (Chic.), 31, 255-261.

Henneberg, R. (1916). Über Genuine Narcolepsie. Neurologisches Zentralblatt, 35, 282-290.

Hishikawa, Y., and Kaneko, Z. (1965). Electroencephalo- graphic study of narcolepsy. Electroencephalography and Clinical Neurophysiology, 18, 249-259.

Hishikawa, Y., Ida, H., Nakai, K., and Kaneko, Z. (1966). Treatment of narcolepsy with imipramine and desmethylimipramine. Journal of the Neurological Sciences, 3, 433-461.

Jouvet, M. (1960). Telencephalic and rhombencephalic sleep in the cat. In The Nature of Sleep, pp. 188-206. Edited by G. E. W. Wolstenholme and M. O'Conner. Little Brown: Boston.

Keefe, W. P., Yoss, R. E., Martens, T. G., and Daly, D. D. (1960). Ocular manifestations of narcolepsy. American Journal of Ophthalmology, 49,953-957.

Levin, M. (1932). Cataplexy, Brain, 55, 397-405.

Levin, M. (1943). Diplopia in narcolepsy. Archives of Ophtha!mology, 29,942-955

Mitler, M., and Dement, W. (1974). Cataplectic-like behaviour in cats after microinjections of carbachol in pontine reticular formation. Brain Research, 68, 335-343.

Parkes, J. D., Fenton, G., Struthers, G., Curzon, G., Kantamanent, B. D., Buxton, B. H., and Record, C. (1974). Narcolepsy and cataplexy. Clinical features, treatment and cerebrospinal fluid findings. Quarterly Journal of Medicine, 172, 525-526.

Pohl, O. (1966). Ein Beitrag zur Pathologie der Symptomatischen Narkolepsie. Deutsche Zeitschrift fur Nervenheilkunde, 189, 211-217.

Rechtschaffen, A., Wolpert, E. A., Dement, W. C., Mitchell, S. A., and Fisher, C. (1963). Nocturnal sleep of narcoleptics. Electroencephalography and Clinical Neurophysiology, 15, 599-609.

Roth, B., Brůhov́a, S., and Lehovský, M. (1969). REM sleep and NREM sleep in narcolepsy and hypersomnia. Electroencephalography and Clinical Neurophysiology, 26, 176-182.

Shapiro, W. R. (1975). Treatment of cataplexy with clomipramine. Archives of Neurology (Chic.), 32, 653-656.

Suzuki, J. (1966). Narcoleptic syndrome and paradoxical sleep. Folia Psychiatrica et Neurologica Japonica, 20, 123-149.

Tridon, P., Montant, J., Picard, L., Weber, M., and André, J. M. (1969). Syndrome de Gélineau et haemangioblastome kystique de cervelet. Revue Neurologique, 121, 186-189.

Van Bogaert, L. (1926). Syndrome de la calotte protin bérantielle avec myoclonus localisées et troubles du sommeil. Revue Neurologique, 45, 977-988. 